\title{
The screening and characterization of 6-aminopurine-based xanthine oxidase inhibitors
}

\author{
Jung-Feng Hsieh, ${ }^{\text {a }}$ Shih-Hsiung Wu, ${ }^{\text {a,b }}$ Yu-Liang Yang, ${ }^{a}$ \\ Kee-Fong Choong ${ }^{\mathrm{a}}$ and Shui-Tein Chen ${ }^{\mathrm{a}, \mathrm{b}, *}$ \\ anstitute of Biological Chemistry and the Genomics Research Center, Academia Sinica, Nankang, Taipei 115, Taiwan \\ ${ }^{\mathrm{b}}$ Institute of Biochemical Science, National Taiwan University, Taipei 106, Taiwan
}

Received 1 February 2007; revised 5 March 2007; accepted 5 March 2007

Available online 12 March 2007

\begin{abstract}
Xanthine oxidase (XO) is a key enzyme which can catalyze xanthine to uric acid causing hyperuricemia in humans. By using the fractionation technique and inhibitory activity assay, an active compound that prevents XO from reacting with xanthine was isolated from wheat leaf. It was identified by the Mass and NMR as 6-aminopurine (adenine). A structure-activity study based on 6-aminopurine was conducted. The inhibition of XO activity by 6-aminopurine $\left(\mathrm{IC}_{50}=10.89 \pm 0.13 \mu \mathrm{M}\right)$ and its analogues was compared with that by allopurinol $\left(\mathrm{IC}_{50}=7.82 \pm 0.12 \mu \mathrm{M}\right)$. Among these analogues, 2-chloro-6(methylamino)purine $\left(\mathrm{IC}_{50}=10.19 \pm 0.10 \mu \mathrm{M}\right)$ and 4-aminopyrazolo[3,4- $\left.d\right]$ pyrimidine $\left(\mathrm{IC}_{50}=30.26 \pm 0.23 \mu \mathrm{M}\right)$ were found to be potent inhibitors of XO. Kinetics study showed that 2-chloro-6(methylamino)purine is non-competitive, while 4-aminopyrazolo[3,4- $d$ ]pyrimidine is competitive against XO.

(C) 2007 Elsevier Ltd. All rights reserved.
\end{abstract}

\section{Introduction}

Xanthine oxidase (XO, EC 1.2.3.2) can be found at the end of the catabolic sequence of the purine nucleotide metabolism in humans and a few other uricotelic species. ${ }^{1}$ It catalyzes the oxidation of xanthine and transforms it into uric acid. The overproduction of uric acid can cause hyperuricemia and gout, as uric acid is deposited in joints and thus causing painful inflammation. ${ }^{2,3}$ Accordingly, the use of the XO inhibitor that blocks the synthesis of uric acid in the body should be one of the therapeutic approaches for the treatment of gout. ${ }^{4}$ Allopurinol (1H-pyrazolo[3,4- $\left.d\right]$ pyrimidin-4-ol) is a substrate and a specific potent inhibitor for $\mathrm{XO}$, and has been used for gout treatment for a number of years. The synthetic analogues of allopurinol, pyrazolopyrimidine, 1-phenylpyrazoles, cytokinin are also used as XO inhibitors. ${ }^{5,6}$ The inhibition mechanism and molecular modeling studies of these analogues also have been conducted by scientists. ${ }^{7,8}$

Keywords: Allopurinol; 6-Aminopurine; 2-Chloro-6(methylamino)purine; Inhibitor.

* Corresponding author. Tel.: +886 2 27886230; fax: +886 2 27883473; e-mail: bcchen@gate.sinica.edu.tw
Recently, several studies have indicated that allopurinol may induce hypersensitivity syndrome and Stevens-Johnson syndrome in patients. ${ }^{9-12}$ Therefore, many Vietnamese medicinal plants have been evaluated for their XO inhibitory property in the treatment of gout. Among 288 extracts prepared from 96 medicinal plants, 188 demonstrated $\mathrm{XO}$ inhibitory activity at $100 \mu \mathrm{g} / \mathrm{mL} .^{13,14}$ Active compounds were also purified from botanical plants. For examples, the valoneic acid dilactone isolated from the leaves of Lagerstroemia speciosa showed a potent inhibitory effect on $\mathrm{XO}$ in a non-competitive mode. ${ }^{15}$ Furthermore, liquiritigenin and isoliquiritigenin isolated from Sinofranchetia chinensis also have high XO inhibitory activity. ${ }^{16}$

In this study, we purified an active compound (6-aminopurine) from water extract of wheat leaf. We found that this compound is a good substrate for $\mathrm{XO}$, and the final product (2,8-dihydroxyadenine) can prevent $\mathrm{XO}$ from reacting with xanthine in inhibitory activity assay. Therefore in this paper, we focused the structure-activity study on 6-aminopurine and its analogues, and investigated their XO inhibitory potency. 


\section{Results and discussion}

\subsection{Isolation of active compound from wheat leaf}

The procedure for fractionation of the extracts from fresh wheat leaves is shown in Figure 1. Wheat sample $(2.2 \mathrm{~L})$ was extracted from $3660 \mathrm{~g}$ of wheat leaves. The sample was then heated to $85^{\circ} \mathrm{C}$ for $10 \mathrm{~min}$, and the supernatant was then freeze-dried to yield $98 \mathrm{~g}$ of the water extract which displayed the XO inhibitory activity $\left(\mathrm{IC}_{50}=181.6 \mu \mathrm{g} / \mathrm{mL}\right)$. The sample $(10.0 \mathrm{~g})$ was first subjected to the HPLC chromatogram and this set of steps was repeated. Seven fractions (Fr.) were collected with the elution time of $0-4,4-6.5,6.5-10,10-19,19-23$, 23-41, and 41-59 min, respectively (Fig. 2). A total of seven fractions were collected and the total yield of these fractions was $87.1 \%$, while the yield of each fraction was $14.7 \%, 18.1 \%, 21.3 \%, 4.9 \%, 3.8 \%, 17.2 \%$ and $7.1 \%$, respectively. Seven fractions were then used to inhibit $\mathrm{XO}$ at the concentration of $200 \mu \mathrm{g} / \mathrm{mL}$, the XO inhibitory activity was $11.3 \%, 73.3 \%, 11.1 \%, 2.5 \%, 6.3 \%$, $9.6 \%$ and $14.1 \%$, respectively (Fig. 3). Among those fractions, the second fraction (Fr. 2) had the highest XO inhibitory activity. Fr.2 $(1.81 \mathrm{~g})$ was then undergoing next preparative HPLC chromatogram (Fig. 4). Individual peak was collected and used to inhibit XO. Consequently, one pure compound (arrow) was isolated and had the inhibitory property. This compound was collected, and the total yield was $2.7 \%$ (48.9 mg) in Fr.2.

\subsection{Identification of active compound}

The active compound isolated from wheat leaf was analyzed by using a high-resolution ESI-TOF mass spectrometer, and its molecular weight was found to be 136.0647. This compound was then analyzed by using a NMR, and the results are shown. $2 \mathrm{D}^{1} \mathrm{H}^{-13} \mathrm{C}$ HMBC spectra were recorded with ${ }^{2} J$ or ${ }^{3} J \mathrm{H}-\mathrm{C}$ coupling constants at 8 and $5 \mathrm{~Hz}, 2 \mathrm{D}{ }^{1} \mathrm{H}-{ }^{13} \mathrm{C}$ HSQC spectra were recorded with ${ }^{1} J \mathrm{H}-\mathrm{C}$ coupling constants at $145 \mathrm{~Hz} .{ }^{1} \mathrm{H}$ NMR: 8.29 (s, 1H, H-8), 8.35 (s, 1H, H-2). ${ }^{13} \mathrm{C}$ NMR:

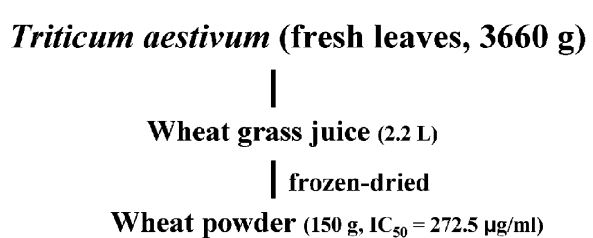

Wheat powder $\left(150 \mathrm{~g}, \mathrm{IC}_{50}=272.5 \mu \mathrm{g} / \mathrm{ml}\right)$ ext. with $\mathrm{H}_{2} \mathrm{O}$ at $85^{\circ} \mathrm{C}$ for $10 \mathrm{~min}$

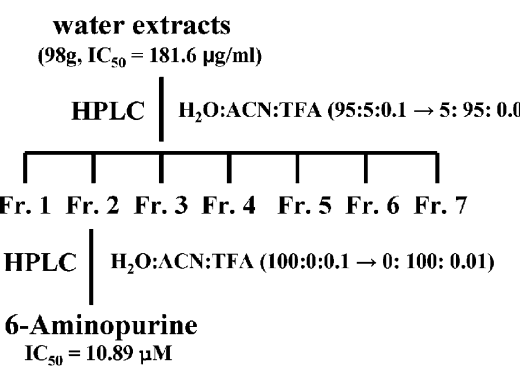

Figure 1. Procedure for fractionation of the extracts from fresh leaves of wheat (Triticum aestivum L.).

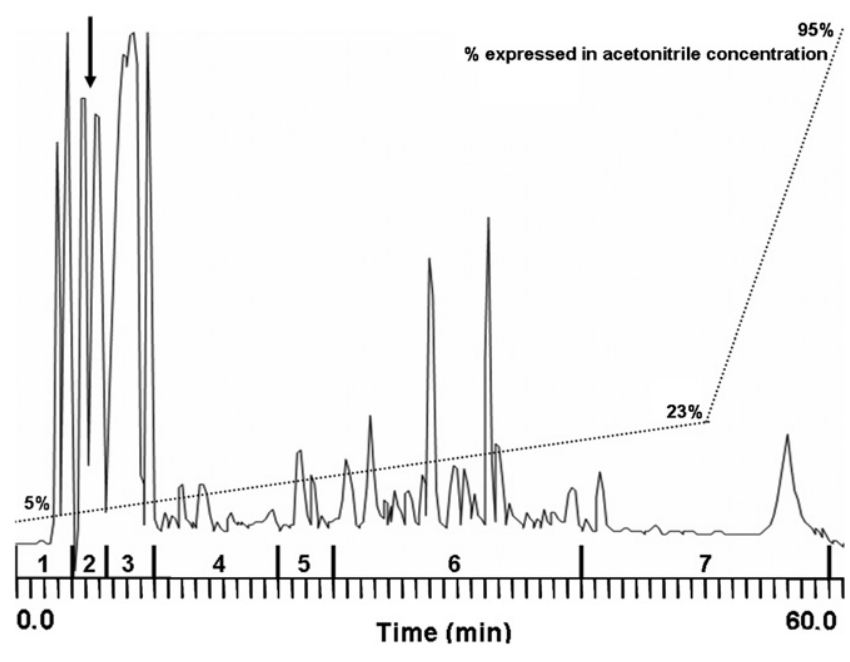

Figure 2. Preparative HPLC chromatogram of water extracts fractionated from water extracts. Column: C18 $(10 \mathrm{~mm} \times 250 \mathrm{~mm}, 5 \mu \mathrm{m}$ Spherical, Advanced Separation Technologies, Inc.). Mobile phase: a gradient elution with $\mathrm{H}_{2} \mathrm{O}$ /acetonitrile/trifluoroacetic acid (95:5:0.1, $\mathrm{v} / \mathrm{v} / \mathrm{v}, \rightarrow$ 5:95:0.01, v/v/v). Flow rate: $4.0 \mathrm{~mL} / \mathrm{min}$. Detection: UV $214 \mathrm{~nm}$. Seven fractions (Fr.) were obtained which were collected at the elution time of $0-4,4-6.5,6.5-10,10-19,19-23,23-41$, and 41-59 min, respectively.

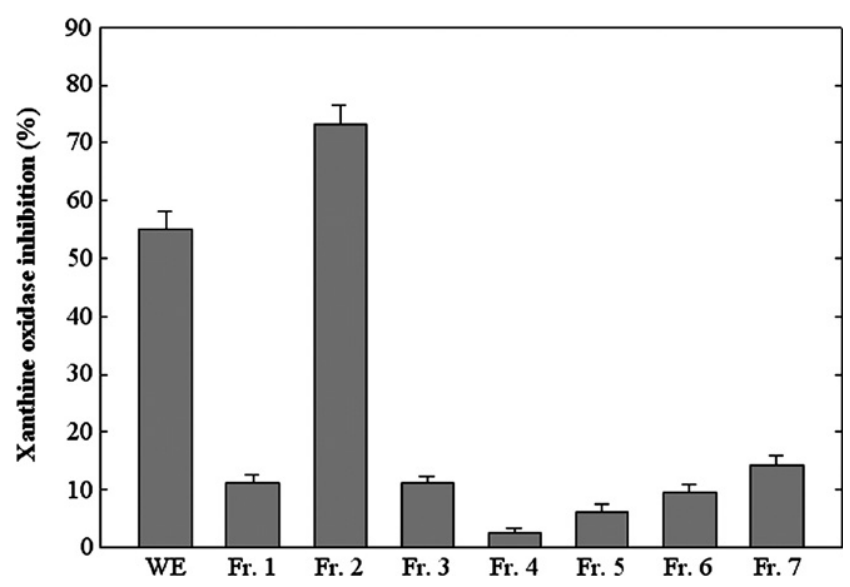

Figure 3. Inhibition of xanthine oxidase by water extracts and its fractions at a final concentration of $200 \mu \mathrm{g} / \mathrm{mL}$. Each value is represented as mean \pm SD from triplicate measurements.

115.8 (H-5), 142.3 (H-8), $148.4(\mathrm{H}-2), 149.7$ (H-4), 152.4 (H-6). On the basis of the above data, this active compound was identified as 6-aminopurine (adenine) by direct comparison with an authentic sample. The molecular formula of 6-aminopurine is $\mathrm{C}_{5} \mathrm{H}_{5} \mathrm{~N}_{5}$, and the chemical structure is shown in Figure 5. This compound is a naturally occurring nucleic acid base in normal cells, which plays an essential role in the replication of all known living systems. ${ }^{17}$

\subsection{Reaction scheme for the xanthine oxidase on allopu- rinol and 6-aminopurine}

As mentioned previously, the conversions of hypoxanthine to xanthine and xanthine to uric acid were catalyzed by XO in the breakdown pathway of purines. ${ }^{1}$ The reaction scheme for xanthine oxidase on allopurinol 


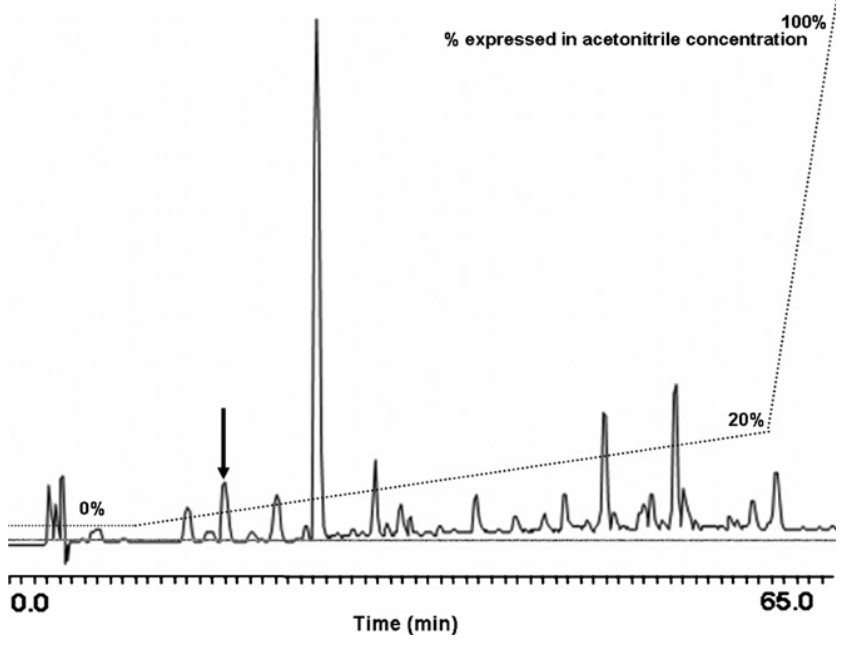

Figure 4. Preparative HPLC chromatogram of Fr. 2 fractionated from water extracts. Column: C18 $(10 \mathrm{~mm} \times 250 \mathrm{~mm}, 5 \mu \mathrm{m}$ Spherical, Advanced Separation Technologies, Inc.). Mobile phase: a gradient elution with $\mathrm{H}_{2} \mathrm{O}$ /acetonitrile/trifluoroacetic acid (100:0:0.1, v/v/v, $\rightarrow$ 0:100:0.1, v/v/v). Flow rate: $4.0 \mathrm{~mL} / \mathrm{min}$. Detection: UV $214 \mathrm{~nm}$. Arrow: active compound (6-aminopurine).<smiles>Nc1ncnc2[nH]cnc12</smiles>

\section{6-Aminopurine}

$\mathrm{C}_{5} \mathrm{H}_{5} \mathrm{~N}_{5}$
Exact Mass: 135.05
Mol. Wt.: 135.13
m/e: 135.05 (100.0\%), $136.06(5.5 \%), 136.05(1.8 \%)$
C, 44.44; $\mathrm{H}, 3.73 ; \mathrm{N}, 51.83$

Figure 5. Chemical structure of 6-aminopurine (adenine).

and 6-aminopurine is shown in Figure 6. Allopurinol is a drug used as XO inhibitor in gout treatment. ${ }^{18}$ It is a substrate and specific potent inhibitor for XO, but oxypurinol (1H-pyrazolo[3,4- $d]$-pyrimidine-4,6-diol) is the basic functioning ingredient found in allopurinol. XO could catalyze the allopurinol to oxypurinol, and inhibi- tion occurs mainly through direct substrate competition in the breakdown of purines. ${ }^{8}$ However, allopurinol is a competitive inhibitor of $\mathrm{XO}$, while its active metabolite (oxypurinol) is a non-competitive inhibitor of XO. ${ }^{19,20}$ This reaction has the effect of reducing the amount of concentration of insoluble urates in tissues, plasma, and urine, which leads to the reversal of urate crystal deposits in tissues and uric acid stones. ${ }^{21} \mathrm{XO}$ also could catalyze 6-aminopurine to 8-hydroxyadenine and 2,8dihydroxyadenine (the final product) then inhibited $\mathrm{XO} .{ }^{22}$ Based on the structure of 6-aminopurine, we have selected 6-aminopurine and its analogues for XO inhibitory activity assay (Table 1).

\subsection{XO inhibitory activity of 6-aminopurine and its analogues}

The purified 6-aminopurine from wheat leaf showed its $\mathrm{XO}$ inhibitory property, and we further investigated the XO inhibitory property of its analogues. XO inhibitory activity was evaluated and compared with the allopurinol. Allopurinol is a clinically used XO inhibitor, and its $\mathrm{IC}_{50}$ value was $5.43 \mu \mathrm{M} .^{23}$ The structure and $\mathrm{IC}_{50}$ of allopurinol and 6-aminopurine analogues are shown in Table 1. Allopurinol, 2-chloro-6(methylamino)purine, 6-aminopurine, and 4-aminopyrazolo[3,4- $d$ pyrimidine showed a strong inhibitory effect on XO, and the $\mathrm{IC}_{50}$ of these compounds were $7.82 \pm 0.12$, $10.19 \pm 0.10,10.89 \pm 0.13$, and $30.26 \pm 0.23 \mu \mathrm{M}$, respectively. Moreover, 5-nitrobenzimidazole and 6-thioguanine showed a slight inhibitory effect on $\mathrm{XO}$, and the $\mathrm{IC}_{50}$ of these compounds were $86.84 \pm 0.51$ and $92.42 \pm 0.62$, respectively. But the other 6 -aminopurine analogues did not show any significant inhibitory effect on XO.

2.5. Inhibitory property of allopurinol, 6-aminopurine, 2-chloro-6(methylamino)purine, and 4-aminopyrazolo[3,4- $d]$ pyrimidine on $\mathrm{XO}$

$\mathrm{XO}$ is a complex enzyme containing molybdenum and the catalytic mechanism of oxidation is thought to involve hydride transfer from the substrate in concert with nucleophile transfer to the same substrate. The<smiles>Nc1ncnc2[nH]cnc12</smiles>
6-aminopurine

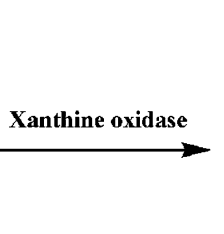<smiles>Oc1ncnc2[nH]ncc12</smiles><smiles>Nc1ncnc2[nH]c(Cl)nc12</smiles>

8-hydroxyadenine<smiles>Nc1nc(O)nc2[nH]c(O)nc12</smiles>

2,8-dihydroxyadenine<smiles>[Y]C(C)C</smiles><smiles>Oc1nc(O)c2cn[nH]c2n1</smiles>

oxypurinol

Figure 6. Reaction scheme for the xanthine oxidase-mediated conversion of 6-aminopurine to 2,8-dihydroxyadenine and suicide inhibitor allopurinol to the deadend inhibitor, oxypurinol. 
Table 1. Structure and $\mathrm{IC}_{50}$ values of allopurinol and 6-aminopurine analogues

\begin{tabular}{|c|c|c|c|}
\hline Serial number & Compound & Structure & $\mathrm{IC}_{50} \pm \operatorname{SEM}(\mu \mathrm{M})$ \\
\hline 1 & Allopurinol & & $7.82 \pm 0.12$ \\
\hline 2 & 2-Chloro-6(methylamino)purine & & $10.19 \pm 0.10$ \\
\hline 3 & 6-Aminopurine & & $10.89 \pm 0.13$ \\
\hline 4 & 4-Aminopyrazolo[3,4- $d]$ pyrimidine & & $30.26 \pm 0.23$ \\
\hline 5 & 5-Nitrobenzimidazole & & $86.84 \pm 0.51$ \\
\hline 6 & 6-Thioguanine & & $92.42 \pm 0.62$ \\
\hline 7 & 2-Aminopurine & & $>200$ \\
\hline 8 & $1,2,4$-Triazolo $[1,5-a]$ pyrimidine & & $>200$ \\
\hline 9 & 6-O-Methylguanine & & $>200$ \\
\hline 10 & 2-Amino-6-chloropurine & & $>200$ \\
\hline 11 & 5-Methylbenzimidazole & & $>200$ \\
\hline 12 & 2,6-Diaminopurine & & $>200$ \\
\hline 13 & 5,6-Dimethylbenzimidazole & & $>200$ \\
\hline
\end{tabular}

inhibitory effects of allopurinol, 6-aminopurine, 2-chloro-6(methylamino)purine, and 4-aminopyrazol$\mathrm{o}[3,4-d]$ pyrimidine on XO were tested at different concentrations. As shown in Figure 7, XO inhibition increased significantly with the addition of allopurinol. In this study, allopurinol is used as the standard inhibitor and it decreases the production of uric acid by inhibiting the action of XO. It is a structural analogue of 


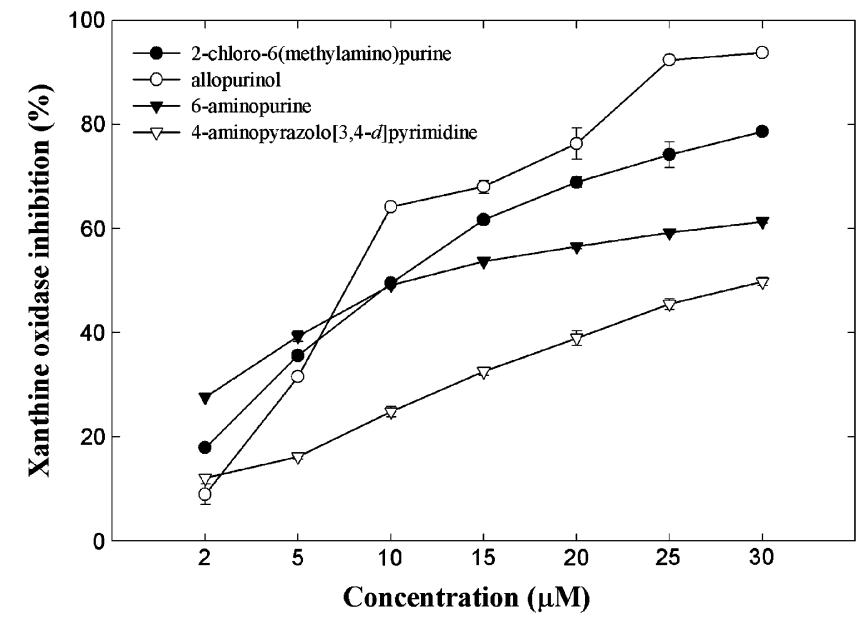

Figure 7. Inhibitory effects of allopurinol, 2-chloro-6(methylamino)purine, 6-aminopurine, and 4-aminopyrazolo[3,4- $d]$ pyrimidine on $\mathrm{XO}$ activity. Each point described indicates the average $\pm \mathrm{SD}$ of triplicate measurements.

hypoxanthine and represents a competitive inhibitor of $\mathrm{XO}$, which can compete with substrate for the active site of XO to form the XO-inhibitor complex. ${ }^{24}$ Furthermore, similar trends were also observed in the results of 2-chloro-6(methylamino)purine, 6-aminopurine and 4-aminopyrazolo[3,4- $d]$ pyrimidine. The XO inhibition reached a maximum when $30 \mu \mathrm{M}$ of inhibitors was added, while the XO inhibition of allopurinol, 6-aminopurine, 2-chloro-6(methylamino)purine, and 4-aminopyrazolo[3,4- $d$ pyrimidine was $93.8,61.3,78.6$, and $49.8 \%$, respectively. The results also showed that low concentrations $(2-5 \mu \mathrm{M})$ of 2-chloro-6(methylamino)purine and 6-aminopurine demonstrated a higher XO inhibition than allopurinol and 4-aminopyrazol$\mathrm{o}[3,4-d]$ pyrimidine, while high concentrations $(20-30 \mu \mathrm{M})$ of allopurinol and 2-chloro-6(methylamino)purine demonstrated a higher $\mathrm{XO}$ inhibition than 6-aminopurine and 4-aminopyrazolo[3,4- $d]$ pyrimidine. According to the results, 4-aminopyrazolo[3,4-d]pyrimidine and 2-chloro-6(methylamino)purine have the potential to be XO inhibitor. We noticed that the metabolism of 4-aminopyrazolo[3,4- $d]$ pyrimidine has been studied in several normal and neoplastic mouse tissues. ${ }^{25}$ Moreover, the administration of 4-aminopyrazolo $[3,4-d]$ pyrimidine decreased serum cholesterol level in the rat. ${ }^{26}$ However, we did not find any possible toxicity information of 2-chloro-6(methylamino)purine in animal and human.

The inhibition kinetics of 4-aminopyrazolo[3,4- $d$ ]pyrimidine and 2-chloro-6 (methylamino)purine on XO were also evaluated. Lineweaver-Burk plots of 4-aminopyrazolo[3,4- $d]$ pyrimidine and 2-chloro-6(methylamino)purine are shown in Figures 8 and 9. The 4-aminopyrazolo[3,4- $d$ ] pyrimidine showed its competitiveness against $\mathrm{XO}$, this result coincided with a previously published data. ${ }^{7}$ This indicated that 4-aminopyrazolo[3,4-d]pyrimidine could compete with xanthine for the active site of $\mathrm{XO}$ to form the XO-inhibitor complex. As we know, 4-aminopyrazolo[3,4- $d]$ pyrimidine

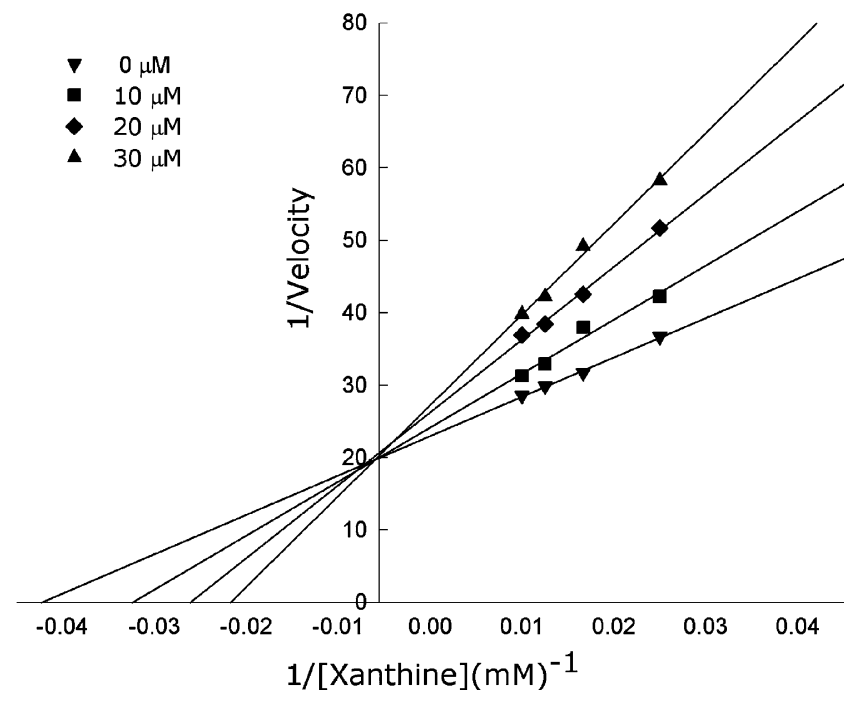

Figure 8. Lineweaver-Burk plots for the inhibition of xanthine oxidase by 4-aminopyrazolo[3,4- $d]$ pyrimidine (AP) with xanthine as substrate. $\boldsymbol{\nabla}$, without AP; $\mathbf{\square}$, with $10 \mu \mathrm{M}$ AP; $\diamond$, with $20 \mu \mathrm{M}$ AP; $\boldsymbol{\Lambda}$, with $30 \mu \mathrm{M}$ AP.

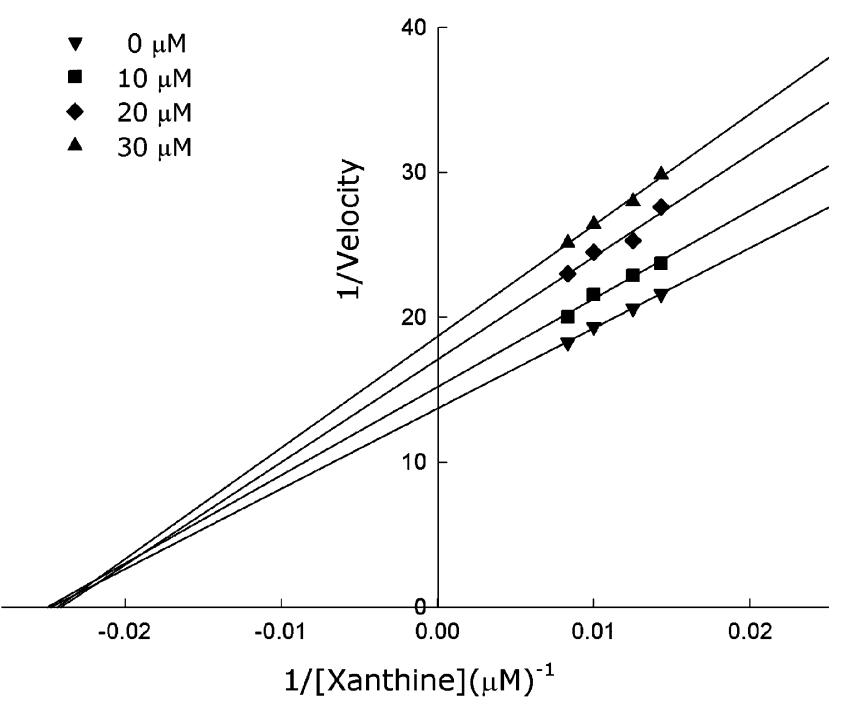

Figure 9. Lineweaver-Burk plots for the inhibition of xanthine oxidase by 2-chloro-6(methylamino)purine (CP) with xanthine as substrate. $\boldsymbol{\nabla}$, without CP; $\mathbf{\square}$, with $10 \mu \mathrm{M} \mathrm{CP} ;$, with $20 \mu \mathrm{M} \mathrm{CP}$; $\boldsymbol{\Lambda}$, with $30 \mu \mathrm{M} \mathrm{CP}$.

and allopurinol are competitive inhibitors of XO. According to their structures and $\mathrm{IC}_{50}$ values (Table 1), $\mathrm{XO}$ inhibition of compound with $\mathrm{OH}$ group at C-4 position was higher than $\mathrm{NH}_{2}$ group. In addition, 2-chloro-6(methylamino)purine showed its non-competitiveness against XO. However, in contrast, 4-aminopyrazolo[3,4- $d$-pyrimidine is competitive inhibitor of $\mathrm{XO}$. The inhibition of XO by 2-chloro-6(methylamino)purine is non-competitive. Although its binding sites and mechanism of inhibition remain to be determined, the finding of non-competitive inhibition suggests that 2-chloro6(methylamino)purine may interact with XO domains distal to the substrate binding site, possibly resulting in allosteric effects that attenuate XO activity. 


\section{Conclusions}

Based on the structure of 6-aminopurine, we have selected its analogues for XO inhibitory activity assay. The 4-aminopyrazolo-[3,4- $d]$ pyrimidine showed its competitiveness against XO, while 2-chloro-6(methylamino)purine showed a potent inhibitory effect on $\mathrm{XO}$ in a non-competitive mode. Furthermore, the $\mathrm{IC}_{50}$ of 2-chloro-6(methylamino)purine was similar to that of allopurinol which is a well-known XO inhibitor clinically used for gout treatment. Therefore, our results suggested that 2-chloro-6(methylamino)purine and 4-aminopyrazolo[3,4- $d]$ pyrimidine are likely to be adopted as candidates to treat gout and may be taken for further evaluation in in vivo studies.

\section{Experimental}

\subsection{Preparation of wheat extracts}

Wheat leaf (Triticum aestivum L.) was grown individually in $30 \mathrm{~cm}$ diameter $\times 15 \mathrm{~cm}$ high containers in an element controlled environment with the temperature ranging from 18 to $24^{\circ} \mathrm{C}$ and $16 \mathrm{~h}$ of sun light per day for a period of 10 days. After harvesting, wheat leaf was milled by a laboratory-scale milling machine and the pulp was filtered through filter paper. The sample collected $(2.2 \mathrm{~L})$ was heated to $85^{\circ} \mathrm{C}$ for $10 \mathrm{~min}$. After $15 \mathrm{~min}$ of centrifugation at $12,000 \mathrm{~g}$, the supernatant was freeze-dried to yield $98 \mathrm{~g}$ of the water extract. Specimen was stored at $-80{ }^{\circ} \mathrm{C}$ before use.

\subsection{Isolation of active compound from water extracts}

Water extract (10 g) was re-dissolved in $200 \mathrm{~mL}$ of water and underwent column chromatography on a HPLC by using C18 packed column (10 mm $250 \mathrm{~mm}, 5 \mu \mathrm{m}$ Spherical, Advanced Separation Technologies, Inc.) and a gradient elution from $\mathrm{H}_{2} \mathrm{O} /$ acetonitrile/trifluoroacetic acid (100:0:0.001) to $\mathrm{H}_{2} \mathrm{O} /$ acetonitrile/trifluoroacetic acid (0:100:0.001) was performed to isolate the main active compound. The elution began with solvent at a flow rate of $4 \mathrm{~mL} / \mathrm{min}$, and the compound with $\mathrm{XO}$ inhibitory activity was then collected.

\subsection{Assay of XO inhibitory activity}

The XO inhibitory activity was assayed spectrophotometrically at $295 \mathrm{~nm}$ under aerobic condition. ${ }^{27,28}$ The reaction mixture contained $200 \mathrm{mM}$ sodium pyrophosphate buffer ( $\mathrm{pH} 7.5), 100 \mu \mathrm{M}$ xanthine, and $0.05 \mathrm{U}$ of XO. The absorption rate at $295 \mathrm{~nm}$ indicates the formation of uric acid at $25^{\circ} \mathrm{C}$. Sample was dissolved directly in the buffer and incorporated with the enzyme assay to assess the inhibitory activity. The experiment was carried out with three sets of apparatus testing XO inhibitory activity and samples were tested further to ascertain the corresponding $\mathrm{IC}_{50}$ values.

\subsection{Mass spectrometry and NMR spectroscopy}

The active compound was analyzed by using a high-resolution ESI-TOF mass spectrometer (BioTOF III; Bru- ker Daltonics, Inc. Billerica, MA, USA). NMR spectra of this compound in $\mathrm{D}_{2} \mathrm{O}$ were recorded on the Bruker Avance 400 spectrometer at $300 \mathrm{~K}$, with standard pulse sequences provided by Bruker.

\subsection{Screening of XO inhibitors from 6-aminopurine analogues}

The 6-aminopurine-based compounds selected for this study include 2-chloro-6(methylamino)purine, 6-thioguanine, 5-nitrobenzimidazole, 4-aminopyrazolo[3,4- $d]$ pyrimidine, 6- $O$-methylguanine, 2-aminopurine, 1,2,4-triazolo[1,5-a]pyrimidine, 5-methylbenzimidazole, 2,6-diaminopurine, 5,6-dimethylbenzimidazole, and 2-amino-6-chloropurine. All samples were tested for $\mathrm{XO}$ inhibitory activity at different concentrations $(2,5$, $10,15,20,25,30,50,100$, and $200 \mu \mathrm{M})$.

\subsection{Lineweaver-Burk plots}

To determine the mode of inhibition by 2-chloro-6(methylamino)purine and 4-aminopyrazolo[3,4- $d]$ pyrimidine, Lineweaver-Burk plot analysis was performed. This kinetics study was carried out in the absence and presence of inhibitors with varying concentrations of xanthine as the substrate. The initial velocity was expressed as the absorbance rate at $295 \mathrm{~nm}$ per $10 \mathrm{~s}$ in the assay.

\section{Acknowledgment}

We thank the National Science and Technology Program for Agricultural Biotechnology, Taiwan (95S0401), for the grant support.

\section{References and notes}

1. Rundles, R. W.; Wyngaarden, J. B. Annu. Rev. Pharmacol. 1969, 9, 345 .

2. Rasaratnam, I.; Christophidis, N. Aust. Fam. Physician 1995, 24, 849 .

3. Harris, M. D.; Siegel, L. B.; Alloway, J. A. Am. Fam. Physician 1999, 59, 925.

4. Emmerson, B. T. N. Engl. J. Med. 1996, 334, 445.

5. Tamta, H.; Thilagavathi, R.; Chakraborti, A. K.; Mukhopadhyay, A. K. J. Enzyme Inhib. Med. Chem. 2005, 20, 317.

6. Ishibuchi, S.; Morimoto, H.; Oe, T.; Ikebe, T.; Inoue, H.; Fukunari, A.; Kamezawa, M.; Yamada, I.; Naka, Y. Bioorg. Med. Chem. Lett. 2001, 11, 879.

7. Sheu, S. Y.; Lin, Y. C.; Chiang, H. C. Anticancer Res. 1997, 17, 1043

8. Tamta, H.; Kalra, S.; Mukhopadhyay, A. K. Biochemistry (Mosc.) 2006, 71, S49.

9. Hammer, B.; Link, A.; Wagner, A.; Bohm, M. Dtsch. Med. Wochenschr. 2001, 126, 1331.

10. Bashir, S.; Shah, S. M.; Babar, I. J. Pak. Med. Assoc. 2000, 50, 207.

11. Elion, G. B.; Kovensky, A.; Hitchings, G. H.; Metz, E.; Rundles, R. W. Biochem. Pharmacol. 1966, 15, 863.

12. Hitchings, G. H. Arthritis. Rheum. 1975, 18, 863.

13. Nguyen, M. T.; Awale, S.; Tezuka, Y.; Tran, Q. L.; Watanabe, H.; Kadota, S. Biol. Pharm. Bull. 2004, 27, 1414. 
14. Kong, L. D.; Cai, Y.; Huang, W. W.; Cheng, C. H.; Tan, R. X. J. Ethnopharmacol. 2000, 73, 199.

15. Unno, T.; Sugimoto, A.; Kakuda, T. J. Ethnopharmacol. 2004, 93, 391.

16. Kong, L. D.; Zhang, Y.; Pan, X.; Tan, R. X.; Cheng, C. H. Cell. Mol. Life Sci. 2000, 57, 500.

17. Shapiro, R. Origins Life Evol. Biosphere 1995, 25, 83.

18. Nguyen, M. T.; Awale, S.; Tezuka, Y.; Ueda, J. Y.; Tran, Q.; Kadota, S. Planta Med. 2006, 72, 46.

19. Fields, M.; Lewis, C. G.; Lure, M. D. Free Radical Biol. Med. 1996, 20, 595.

20. O’Driscoll, J. G.; Green, D. J.; Rankin, J. M.; Taylor, R. R. Clin. Exp. Pharmacol. Physiol. 1999, 26, 779.

21. Rang, H. P.; Dale, M. M.; Ritter, J. M. In Pharmacology; Ritter, J., Ed.; Pergamon Press: New York, 1999; pp 239246.
22. Manfredi, J. P.; Holmes, E. W. Annu. Rev. Physiol. 1985, 47, 691.

23. Fernandes, E.; Carvalho, F.; Silva, A. M.; Santos, C. M.; Pinto, D. C.; Cavaleiro, J. A.; Bastos Mde, L. J. Enzyme Inhib. Med. Chem. 2002, 17, 45.

24. Williams, J. W.; Bray, R. C. Biochem. J. 1981, 195, 753.

25. Henderson, J. F.; Junga, I. G. Cancer Res. 1961, 21, 118.

26. Andersen, J. M.; Dietschy, J. M. Science 1976, 193, 903.

27. Gongora, L.; Manez, S.; Giner, R. M.; Recio Mdel, C.; Schinella, G.; Rios, J. L. Planta Med. 2003, 69, 396.

28. Ferraz Filha, Z. S.; Vitolo, I. F.; Fietto, L. G.; Lombardi, J. A.; Saude-Guimaraes, D. A. J. Ethnopharmacol. 2006, 107, 79 . 